\title{
Understanding the drivers of broadband adoption: the case of rural and remote Scotland
}

\author{
Susan Howick and Jason Whalley \\ Department of Management Science \\ Graham Hills Building \\ 40 George Street \\ Glasgow, UK
}

\begin{abstract}
Broadband has been described as a transforming technology and is now widely available in many developed countries. However, broadband availability is not the same as broadband adoption. If the socio-economic benefits of broadband are to be realised, then adoption needs to be both understood and encouraged. This is particularly important in rural and remote areas. This paper explores the factors that drive broadband adoption in one particular rural and remote area; rural and remote Scotland. A causal model and a quantitative simulation model are developed indicating how the various drivers of adoption interact with one another. Both models show that past policy initiatives have impacted on the rate of adoption. However, the greatest impact could be achieved if future policy initiatives target those people who show no interest in adopting broadband. The paper concludes by suggesting that this work has implications for rural and remote areas all around the world.
\end{abstract}

Keywords: Broadband, rural and remote Scotland, causal diagrams, system dynamics 


\section{Introduction}

National broadband coverage has been a policy objective adopted in many developed countries. Although some countries have advanced towards this goal more than others, an increasing number of countries can now claim to have achieved widespread broadband availability. However, it does not follow that widespread broadband availability automatically leads onto its widespread adoption. Broadband may be seen by some potential adopters as being too costly, whilst others may feel that there is no compelling service that warrants its uptake. Consequently, it is pertinent to ask what factors drive broadband adoption?

If the socio-economic benefits of broadband are to be realised, such as access to educational services or markets located elsewhere, then adoption needs to be both understood and encouraged. This is particularly important in rural and remote areas. It has been argued that rural and remote areas will enjoy significant socio-economic benefits from the introduction of broadband (Scottish Executive, 2001a; 2002), with some going as far as suggesting that broadband will have the same transformational impact as electricity. The introduction of broadband will contribute to the death of distance that telecommunications has so long promised to bring about.

This paper focuses on a specific rural and remote area of the UK, rural and remote Scotland. The paper aims to explore the key drivers of broadband adoption in this area. After presenting an overview of broadband and rural and remote Scotland, broadband availability and adoption are discussed. A model is then presented which identifies the key drivers of broadband adoption in rural and remote Scotland and how they interact with one another. The paper closes with recommendations for future policy initiatives in this area.

\section{Broadband}

There is no agreed definition of broadband. Although the ITU states that broadband equates to transmission speeds faster than 1.5 or 2 mbps (ITU, 2003: 9), a range of alternative definitions have been suggested. The OECD, for instance, adopts a downstream access threshold of $256 \mathrm{kbps}$, a rate that is slightly faster than the $200 \mathrm{kbps}$ rate adopted by the FCC (ITU, 2006: 21). Ofcom, in contrast, has opted for a broader definition encompassing always on and data rates of at least $128 \mathrm{kbps}$ (Ofcom, 2004). The Ofcom definition is adopted here.

Although there may be some disagreement as to the definition of broadband, it is widely accepted that there are many advantages associated with it (Cava-Ferreruela et al 2006, Varian et al 2002, Vigden et al 2004). These advantages are both economic as well as social. Broadband contributes to national economic competitiveness (ITU, 2003), allowing industry to access distant markets as well as develop and deliver new services. There are also social benefits associated with broadband. The greater download speeds associated with broadband broaden and improve the services that can be offered as part of tele-medicine and tele-education, as well as allow dispersed families to remain in contact through, for instance, the online sharing of pictures or the use of Skype. Whilst Fransman (2006) is not alone in noting that broadband lacks a 'killer application,' it has made the 
downloading of music and videos more attractive and common than was the case with dial-up Internet access.

Drawing on the literature it is possible to identify a range of factors that encourage ICT and broadband adoption. The first identifiable factor is that of cost. Although Bauer et al (2005) argue that the relationship between broadband penetration and cost is not yet fully understood, Geroski (2000) states that cost is an important issue for those dial-up Internet users considering switching to broadband. As broadband Internet access is typically more expensive than its dial-up counterpart, potential switchers who are unaware of the benefits of broadband may be reluctant to pay more for what they perceive to be the same service.

It is worth noting, however, that whilst the difference in price between dial-up and broadband may not be that great, the cost of the service is often not the only cost that has to be considered by potential switchers as new computer equipment and training may also be required. In the late 1990s research found that households in rural America were less likely to own a computer than their urban counterparts, thereby adding to the cost of using the Internet (Strover, 2001). Moreover, Biggs et al (2006) draw attention to broadband pricing and speed trends - drawing on ITU data they show, on average, that between 2003 and 2005 broadband prices have fallen whilst speeds have increased. In other words, broadband prices are falling in absolute terms and are thus less of a barrier to adoption than was previously the case.

Secondly, the attributes or characteristics of broadband can also influence its adoption. Savage et al (2005) identified three such attributes - speed, service reliability and 'always-on' - whose influence on adoption varies depending on the social status of the potential adopter. Potential adopters with higher incomes value these more than those with lower incomes, and those with a degree value speed more, always-on less and reliability about the same as those without a degree. Warren (2004) found that the majority of computer literate farmers struggle with slow connection speeds, with the consequence that the faster speeds of broadband are likely to be attractive to them.

A third factor that can encourage broadband adoption is the social context within which the potential adopted is located. Savage et al (2005) found that broadband adoption is most likely in households with a higher income, college education and multiple computers. Ofcom (2006c: p 64) also draws attention to the supporting role played by friends and family when it comes to learning about digital services and products. Across the UK as a whole, the most popular way to learn about digital products and services was through reading the manual, with the second most popular being through asking friends and family for assistance. Scotland was the only part of the UK where the reverse was found.

Fourthly, would-be adopters should feel a need to use the Internet and that access is best serviced through a broadband connection. In a 2006 survey by Ofcom, a lack of need or interest was found to be the overwhelming reason why the Internet was not used at home (Ofcom, 2006a: p 71). Galloway et al (2005) reported a perceived lack of need among rural small and medium sized enterprises, whilst more broadly in rural England it has been observed that businesses adopt ICT at a significantly slower rate than their urban counterparts (DEFRA, 2005; Warren, 2004). 
A major concern in encouraging broadband adoption is to ensure that some areas are not left behind, as they will not be able to enjoy the advantages that it brings. Within the UK, concern has been expressed about geographically remote areas such as Devon, Cornwall and rural Wales. One area that has received considerable interest is rural and remote Scotland, not least because the Scottish Executive has actively sought to ensure that those in rural and remote areas have the same access to broadband as those within urban areas. Through broadband the economy will be revitalised and population levels stabilised, thereby allowing social services to be provided (Scottish Executive, 2001a). There are many rural and remote areas for which exploration of the drivers of broadband adoption would be beneficial, however, the focus of this paper is on how broadband adoption can be encouraged in rural and remote Scotland.

\section{Scotland}

Located in the north of the British Isles, Scotland is the second largest of the four countries that form the United Kingdom. The population of Scotland is just over five million people, the majority of whom live within the central belt that connects Glasgow in the west with Edinburgh in the east. Around one third of the population live in one of Scotland's six cities, which are shown on Figure 1 (below), with the consequence that population densities vary considerably across Scotland. The highest population densities can be found in Glasgow - 3290 people per square kilometre - and the lowest in the Highlands - 8 people per square (National Statistics, 2003: 19). Figure 1 also highlights the areas served by Scotland's two regional development agencies, Highlands \& Islands Enterprise (HIE) and Scottish Enterprise (SE).

Figure 1: Scotland ABOUT HERE

The Scottish Executive is the devolved government of Scotland. The purview of the devolved government is determined by the Scotland Act 1998. Some policy areas such as education and health are devolved to Edinburgh whilst others like the UK single market and defence were retained in London. Those policy areas that were retained in London are referred to as 'reserved matters' and as telecommunications relates to the UK single market responsibility remained in London. As a consequence, Ofcom regulates all of the industry across the UK. This should not be taken, however, as suggesting that telecommunications policy is decided in London without consultation with others parties. Ofcom has established committees representing each of the four countries within the UK as well as users, and regularly engages in consultation on specific issues. The two Scottish regional development agencies have developed their own broadband initiatives within the wider UK framework, and have sought to influence Ofcom through contributing to consultations.

\section{Broadband availability}

According to a recent report, four technologies are used in the UK to deliver broadband services: digital subscriber line (DSL), cable, fixed wireless access and satellite (Ovum, 
2006). Only two of the technologies are widely available throughout the UK, that is, DSL and cable (Ovum, 2006: 13). However, the dominant broadband technology in rural and remote areas is DSL with the consequence that the role of BT in broadband availability is particularly important.

As befits an incumbent operator, BT owns and maintains telephone exchanges across rural and remote Scotland that have been enabled to provide broadband services in a piecemeal fashion. A substantial number of exchanges were enabled when sufficient numbers of potential broadband users had registered to breach the 'trigger levels' (a threshold of potential users above which BT would enable the exchange for broadband) set by BT. As a consequence of this policy, around 85 per cent of the UK had access to broadband services by April 2004 when BT announced the end of its 'trigger level' scheme. Subsequently, those exchanges that had reached 90 per cent of their trigger level were upgraded more or less immediately whilst all the remaining exchanges with a trigger level were to be upgraded by the summer of 2005. On completion, broadband would be available to around 99.6 per cent of businesses and households across the UK.

In April 2005 BT announced that it would upgrade most, but not all, of its remaining exchanges within Scotland. 378 out of 399 exchanges would be upgraded as a consequence of financial support offered from primarily the Scottish Executive as well as the European Regional Development Fund. Although this increased broadband availability within Scotland, some areas were still without access as not all exchanges were upgraded. In these areas public-private partnerships, such as the Connected Communities project in the Western Isles, have been used to provide broadband services in areas where BT does not do so. This project, which has total capital expenditure of just over $£ 5$ million, delivers broadband to public sector bodies such as schools and hospitals as well as businesses and households through its affiliated ISP (Lattemann et al, 2006). Whilst this project has provided broadband infrastructure where none existed, other public-private partnerships elsewhere in Scotland have improved the quality of the infrastructure that is available.

Finally, it is worth noting that as a consequence of the strategic review of telecommunications on the one hand and the focus of Ofcom on local loop unbundling on the other hand, service competition is possible throughout Scotland (Whalley, 2005). This means that whilst there may be only a single infrastructure owned by BT in many parts of Scotland, competition between different companies is possible at the broadband package level. When the strategy adopted by BT is combined with public-private partnerships and the emergence of service competition, broadband is available throughout Scotland with the consequence that the pertinent question to ask is not how broadband availability can be encouraged but rather what drives broadband adoption. Therefore, this paper focuses on "What are the key drivers of broadband adoption in rural and remote Scotland and which of these drivers should policies focus on to have the greatest impact on encouraging broadband adoption?"

\section{Broadband Adoption}

Although broadband is available to $99.9 \%$ of households and businesses across the UK (Ofcom, 2006a: 37), broadband adoption rates are far lower. As can be seen from the 
table below, Internet adoption varies between $48 \%$ and $59 \%$ depending on which part of the UK is looked at. These figures are, however, for dial-up and broadband Internet households with the consequence that broadband adoption is actually lower.

Table 1: Broadband and PC adoption rates 2005

\begin{tabular}{|l|c|c|c|c|c|}
\hline & UK & England & Scotland & Wales & N Ireland \\
\hline $\begin{array}{l}\text { Internet household } \\
\text { (inc broadband) \% }\end{array}$ & 57 & 59 & 51 & 49 & 48 \\
\hline $\begin{array}{l}\text { Broadband as \% } \\
\text { Internet households }\end{array}$ & 63 & 64 & 60 & 54 & 52 \\
\hline
\end{tabular}

Source: Ofcom (2006a: 54)

Around $36 \%$ of households across the UK are broadband households, though there are considerable differences between England (37.76\%), Scotland (30.6\%), Wales (26.46\%) and Northern Ireland (24.96\%). Significantly Ofcom (2006a: 54) found that the rural and remote areas were more likely to use the Internet, albeit via dial-up, than their urban counterpart with one exception: Scotland. In Scotland, urban adoption of the Internet is greater than that in rural and remote areas.

To gain an understanding of the main factors that contribute to businesses or households deciding to adopt broadband or, more importantly, what hinders their adoption of broadband, information was gathered from three sources: literature on new product diffusion, broadband literature and interviews with key stakeholders in the broadband market in rural and remote Scotland. This information was used to build a causal diagram in order to appreciate how the various drivers of broadband adoption interact with one another. The process used to build up the causal diagram using the above three sources of information will be discussed next.

\section{New Product Diffusion}

New product diffusion is a widely researched issue (for example Rogers 2003) and many new product diffusion models exist in the literature (Mahajan et al 1990; 2000), however one of the most well known and widely used is the Bass model (Bass 1969). Since its introduction, many researchers have proposed extensions to the original form of this model (Mahajan et al 1990; 2000, Parker 1994). In addition, a summary of the applications of the extensions of the Bass model to telecoms can be found in Fildes and Kumar (2002). Due to its wide applicability to many areas of new product diffusion and, in particular, its goodness of fit to technological diffusion of information and telecommunications innovations (Kim and Kim 2004; Teng et al 2002) the Bass model structure was used as a starting point to aid understanding of broadband adoption in rural and remote Scotland.

A causal diagram representing the main elements of the Bass model (Sterman 2000) can be viewed in Figure 2. The Bass diffusion model assumes that adoption for a product stems from two main sources; innovators who adopt the product due to external sources of awareness, usually interpreted as the effect of advertising and from imitators who adopt the product as a result of contact with previous adopters i.e. from word-of-mouth. 
Figure 2: Causal Diagram representing the Bass Diffusion Model ABOUT HERE

Figure 2 highlights three feedback loops. The first is a positive feedback loop; as more people adopt the product, there are more people to communicate its benefits through word-of-mouth and hence further people will adopt. There are also two negative feedback loops; as more people adopt the product, there are less potential adopters left (due to a finite population of potential adopters) to adopt through the effects of either word-ofmouth or advertising.

The new product diffusion literature provided a base model with which to begin considering the drivers of broadband adoption in rural and remote Scotland. The next section discusses how this was extended using the broadband literature and interviews with key stakeholders.

\section{Broadband Literature and Interviews}

Following a review of the broadband literature the first step in the modelling process was to split the population into four categories; households with a dial-up connection, households without a dial-up connection, businesses with a dial-up connection and businesses without a dial-up connection. This split of the population was deemed necessary as it was felt that these categories may have varying drivers to adoption and may also be influenced by differing coefficients of imitation and innovation. In order to reflect the specific situation of broadband adoption in rural and remote Scotland, two areas of the model were expanded as follows:

(i) There are obviously many factors that will influence a potential adopter in their decision to adopt broadband. Many of these can be captured by considering the various decision criteria that are taken account of by a potential adopter. This will consist of the broadband attributes that are considered to be of most importance to potential adopters. These decision criteria will affect the coefficients of innovation and imitation.

(ii) The factors that affect the pool of potential adopters.

In addition to information gained from reviewing literature on broadband, interviews with key stakeholders from the broadband industry in rural and remote Scotland provided clarification on what are considered to be the key drivers and their impact on broadband adoption. The interviewees included senior managers from the Scottish Executive, HIE, Scottish Enterprise Borders, Ofcom, consultants from both a major telecommunications focused practice as well as an independent consultancy. In addition, HIE represent the interests of businesses within the region they serve with the consequence that their views will have been included, albeit indirectly.

Each of the organizations that were interviewed are all keen to understand "What are the key drivers of broadband adoption in rural and remote Scotland and which of these 
drivers should policies focus on to have the greatest impact on encouraging broadband adoption?" HIE and Scottish Enterprise Borders were interested due to the economic benefits that broadband brings, and whilst this is also true of the Scottish Executive they were also motivated to participate by the welfare benefits that broadband may bring. Ofcom, as the telecommunications regulator, has a natural interest in ensuring the functioning of the market and understanding how market failure may be addressed.

Interviewees were asked to comment on the drivers of adoption that were taken from the literature and also asked to expand on these based on their own experiences. The following sections summarise the main drivers that were agreed upon by the interviewees.

\section{Decision Criteria Function}

A decision criteria function for households with dial-up is shown in Figure 3.

Figure 3: Key factors affecting decision criteria for households with dial-up ABOUT HERE

Figure 3 illustrates the key factors which are believed to influence the decision of a householder, who currently has dial-up, on whether or not to adopt broadband. This figure includes factors such as the relative cost of the decision (Scottish Executive, 2001b: 7) as well as whether households use, or would like to use, products and services like digital cameras and Internet shopping (that is, the 'use of other technologies') whose use is enhanced in some way by broadband Internet access (Fransman, 2006; Ofcom, 2006c). Also included is whether households appreciate the attributes of broadband, or have any concerns regarding either the content that is available on the Internet or its security (Ofcom, 2006a). If there are any children within the household, the level of ICT competence is raised with the consequence that adopting broadband is not a great as hurdle as would otherwise be the case (Robertson et al., 2004). In other words, the complexity of adopting broadband is decreased.

It should be noted that the cost of broadband is represented as an exogenous factor. It could be argued that as the total number of adopters increases, the price of broadband falls. However, the regulation of local loop unbundling, which has effectively created a floor price, along with the extensive size of the market reduces the extent to which prices will fall in future.

A feedback loop is identified in Figure 3. This loop shows us that the dial-up users for whom the decision criteria/utility function is highest are those with the highest dial-up costs as they are the heaviest users. Since these users are the most likely to switch to broadband, the average dial-up cost will drop as the heavier users of dial-up migrate to broadband, with the consequence that those dial-up users who remain are those with a lower utility function. This is a balancing or 'goal seeking' feedback loop that indicates that dial-up users will continue to migrate to broadband as long as there are discernible financial benefits in such a move. 
For household without dial-up the decision criteria function is similar to that shown in figure 3, with the following amendments:

1. 'frustration with dial-up' will not occur

2. The financial decision criteria is based on an absolute cost which will include the absolute cost of broadband, cost of a computer and the household's level of income.

The decision criteria function for businesses with dial-up is shown in Figure 4.

Figure 4: Key factors affecting decision criteria for businesses with dial-up ABOUT HERE

Figure 4 shows that for businesses with dial-up the decision on whether or not they should adopt broadband is based on two key factors; the cost and benefit of broadband. The cost involves the relative cost of broadband versus dial-up. An incentive payment may also be available to some businesses (Scottish Enterprise, 2004). In addition, some business may have a perception that costs are higher than they actually are (Scottish Executive, 2001b: 11), however campaigns such as SE/HIE workshops (where technology is demonstrated and the benefits that it brings discussed) may have helped to alleviate this perception. The benefits of broadband are seen to be an appreciation of its attributes and through understanding the potential financial benefits that it could bring to a business. A third factor that is also taken into account is concerns about security. A business will need to ensure that any transactions or information that is processed through broadband will be safe. A feedback loop is identified in Figure 4. This loop is the same as that for households shown in Figure 3. It is a balancing feedback loop that indicates that dial-up business users will continue to migrate to broadband as long as there are discernible financial benefits in such a move.

For businesses without dial-up the decision criteria function is similar to that shown in Figure 4, with the following amendments:

1. frustration with dial-up will not be an influencing factor

2. the financial decision criteria is based on an absolute cost which will include the absolute cost of broadband, any incentive payments if they are available, costs associated with security issues, the income level of the business

3. Campaigns such as the SE/HIE workshops will also promote ICT literacy amongst businesses and hence reduce any perceived complexity which will have a positive effect on the decision criteria

\section{Potential Adopters}

Figure 5 captures the key factors that influence the pool of households without dial-up that are potential broadband adopters. 
A household can only adopt broadband if the infrastructure is available to them and they know that it is available to them. If householders use broadband at work, this results in them having more knowledge about infrastructure availability (Hollifield and Donnermeyer, 2003). In addition, some households simply do not want to use the Internet, or indeed a PC at all. For these people, the internet currently offers no compelling service that would encourage their adoption of broadband (Fransman, 2006) nor are they encouraged by the decline in prices (Brignall, 2006; Ofcom, 2006d: 119). Ofcom (2006a, 2006b) terms this as 'voluntary exclusion' and is currently reported as $24 \%$ of people over the whole of Scotland (Ofcom, 2006b). The two lines across the arrow linking 'broadband availability' and 'perceived availability' indicate a delay in people's perception of the availability of broadband.

Figure 5: Key factors that influence the pool of households without dial-up that are potential broadband adopters

ABOUT HERE

A similar causal diagram to Figure 5 exists for households with dial-up. The only difference is that the factor 'number that don't want internet/PC at all' will have no influence in this situation.

The factors that influence the pool of businesses without dial-up that are potential broadband adopters can be seen in Figure 6.

Figure 6: Key factors that influence the pool of businesses without dial-up that are potential broadband adopters

ABOUT HERE

Figure 6 is very similar to Figure 5. The main difference is that perceived unavailability of broadband infrastructure is influenced by campaigns such as the SE/HIE workshops which will aid in reducing this perception.

\section{Advertising}

In addition to expanding the key factors that affect the decision criteria and pool of potential adopters, there were a number of factors in the literature that impacted the role of advertising in broadband adoption. Figure 7 illustrates the key factors affecting advertising.

The concepts shown in bold are those that appear in figure 2, i.e. they indicate how the factors influencing advertising impact on the original Bass model. In this figure, SE/HIE 
media campaigns include the 'Speak up for Broadband' and 'Broadband for Scotland' promotions. It should be noted that ISP advertising is shown to influence both the coefficient of imitation and innovation. It is believed that although the main influence on the coefficient of imitation is through word-of-mouth with other adopters, the fact that someone has seen ISP advertising will impact the meeting they have with the existing adopter.

Figure 7: Key factors that influence advertising

ABOUT HERE

\section{The impact of policies on the causal diagram}

Bringing together the causal diagrams represented in Figures 2-7 produces an overall casual model for broadband adoption (allowing for all four sub-groups of the population). This model provides a clear explanation of the key drivers of broadband adoption in rural and remote Scotland. This model can be used to consider the impact of past or future policy initiatives to encourage broadband adoption. A number of policy initiatives have been introduced by SE and HIE (Tookey et al., 2006). The following discusses the key initiatives and how they impact on broadband diffusion:

1. TV and website advertising (Speak up for Broadband, Broadband for Scotland). The TV advertising campaigns drew attention to broadband and encouraged individuals to register their interest in broadband on the trigger lists run by BT. This campaign ended when BT decided to upgrade all of its exchanges with trigger lists in place. In contrast, the second campaign is ongoing and is more wide ranging in nature as it seeks to provide impartial and technological neutral advice on broadband for businesses and individuals alike. These impact on the awareness of broadband shown on Figure 7, which in turns impacts on the coefficient of innovation. However, to be influenced by website advertising, access to the Internet, either at home via dial-up or at work, is required.

2. Demonstration of broadband benefits (www.work-global.com, e-business demo centres, touring demonstration bus). These campaigns provide illustrations of broadband in use so that potential adopters can appreciate its attributes. The webbased campaigns provide case studies showing examples of broadband use whilst the touring demonstration bus allows would-be adopters to appreciate these for themselves through a hands-on session. These impact on the appreciation of broadband attributes shown in Figures 3 and 4, which in turn influence the decision criteria for households and businesses.

3. Incentive schemes (Business incentive scheme). These are targeted towards businesses and provide a financial incentive to adopt broadband through subsidising the cost of connection. These are shown as incentive payments in Figure 4 and impact on the relative cost decision, which in turn influences the decision criteria for businesses.

Each of the above policies have impacted the coefficients of innovation and/or imitation, mainly through the decision criteria function. These have therefore had an impact on the rate at which potential adopters have adopted broadband. However, none of 
them have directly impacted the pool of potential adopters, thus restricting the uptake of broadband.

As the causal model indicates that the pool of potential adopters is restricting broadband adoption, it is important to explore whether or not this is a long term constraint. Therefore, to assess the over time behaviour which is produced from the relationships contained in the causal model a quantitative system dynamics (Forrester, 1961; Sterman, 2000) simulation model was produced.

\section{Simulation Model}

System dynamics has been used to understand the diffusion process at an aggregate level in a number of previous studies (Milling 1996; Maier 1998) and to specifically explore the diffusion of telecommunications (Osborne, 1999). The particular value of system dynamics in modelling the diffusion process stems from the large number of factors that influence a potential customer's decision to adopt a product. The influence of these factors on the decision to adopt will vary over time. System dynamics is of particular use to model the behaviour of the impact of these factors over time. (Lyons et al 2003). In addition, the strategic analysis of the diffusion of a new technology will involve variables for whom there is limited data. System dynamics is able to take account of such variables if they are believed to be affect system behaviour (Fildes and Kumar, 2002).

\section{Model Structure}

Figure 8 represents an extract of the System Dynamics simulation model that was built. This figure captures the main factors that influence the adoption rate for businesses without dial-up and reflects the key factors and relationships that were captured in the causal diagram. The remainder of the system dynamics model includes similar structures for businesses with dial-up, households without dial-up and households with dial-up.

Figure 8: Portion of System Dynamics model capturing factors that influence broadband adoption for businesses without dial-up

ABOUT HERE

In order to appreciate how the structure of the quantitative simulation structure relates to the structure of the causal diagram, four key variables can be highlighted:

(i) "bus_ndu_criteria" on the left-hand side of figure 8 represents the decision criteria function for non-dial up businesses. This is influenced by security concerns (bus_security concerns), perceived complexity (bus_ndu_complexity) appreciation of broadband attributes (bus_ndu_attributes) and financial decisions (Bus_ndu_finance)

The decision criteria function is taken to be a weighted average of all the factors that influence it. This is in line with the utility function approach used in diffusion modelling, reviewed by Roberts and Lattin (2000). Others have also adopted such an approach, for example Savage and Waldman (2005) propose a utility function 
to describe how adopters of broadband select between internet service providers. Madden and Simpson (1997) developed a utility function when modelling the adoption of cable broadband services. It is also in line with the technology acceptance model used by Oh et al (2003) which combines factors that contribute to a potential adopter's attitude towards broadband.

(ii) "bus_pot_ndu" in the middle of figure 8 represents the potential non dial-up business adopters. This is influenced by the total number of businesses in rural and remote Scotland (total_bus), the initial proportion of businesses that have dial-up (initial_bus_dialup_users), the number of non-dial-up businesses that have already adopted broadband (business_adopters_no_du), the number of businesses that are simply not interested in broadband (bus_not_interested) and the perceived availability of broadband (perc_bus_avail)

(iii) "word_of_mouth_bus_ndu" in the upper right of figure 8 represents the number of non-dial-up businesses that adopt broadband each time period due to a wordof-mouth experience. As seen in figure 2, this is influenced by the total business population (total_bus), the number of business adopters (bus_adopters_no_du), the number of potential adopters (bus_pot_ndu), the contact rate (bus_ndu_contact_rate), the adoption fraction (bus_ndu_adopt_fraction) and the decision criteria (bus_ndu_criteria).

(iv) "advert_adopt_bus_ndu" in the lower right of figure 8 represents the number of non-dial-up businesses that adopt broadband each time period due to the effect of advertising.

It should be noted that it has been assumed that if non-dial-up users wish to connect to the Internet during the time period being considered, they will move directly to broadband.

\section{Populating the model with data}

Various sources of data were used to populate the model. Some of the data is publicly available, for example the number of households and businesses in rural and remote Scotland (General Register Office for Scotland, 2004; National Statistics, 2003). Another example is the fraction of households using dial-up at the beginning of the simulation run (Ofcom, 2006d; Scottish Executive, 2005). However, for some parts of the model expert judgement was required, for example the future trend for the cost of domestic broadband.

During model construction and after the model had been populated by data, standard system dynamics model validation, or confidence building, tests were carried out (Forrester and Senge 1980; Sterman 2000). There are three commonly used sets of tests; tests of model structure, test of model behaviour and test of policy implications. The tests of model structure involve ensuring the structure and parameters contained in the model are consistent with the knowledge of the system and that all the concepts that are important to the problem are included in the model. The review of the literature and the interviews with interested stakeholders drew out relevant concepts and enabled those involved to gain confidence in the structure of both the qualitative and quantitative models. Gaining confidence in model behaviour involves testing the structure and parameters of the model by observing the resulting behaviour. As a part of this the 
interviewees were asked to produce and discuss reference mode sketches of their view of broadband adoption over a 20-year period for both businesses and households. Standard methods were used for eliciting the reference mode sketches (Andersen and Richardson 1997, Saeed 1998). Finally, tests for policy implications include observing the real system once recommended policies have been implemented to track their actual impact over time. Such tests were not relevant at this stage of the analysis.

\section{System Dynamics Model Output}

Figure 9 shows the number of household and business adopters over a 20-year (i.e. 240 month) period commencing January 2001. This date was chosen as the starting point of the simulation since this corresponded with the introduction of broadband into the market (Ofcom, 2006d). In addition, 2001 also corresponds to the point when the Scottish Executive began to express an interest in broadband (Scottish Executive, 2001a; 2001b; 2002).

The shape of the graphs shown in Figure 9 follow the typical Bass model S-shaped growth. The initial exponential growth arises from the rate of adoption from word-of mouth (i.e. the positive feedback loop shown in figure 2). The growth then slows as the number of potential adopters reduces through saturation of the market (i.e. the negative feedback loops shown in Figure 2). Of particular interest here is the steepness of the curves, especially for householders. Within a 2.5 year period (month 60 to month 90 ) the percentage of households with broadband increases from approximately $13 \%$ to $60 \%$.

A second feature of Figure 9 is that business adoption is lagging behind household adoption. This can be largely explained by the types of businesses that exist in rural and remote Scotland. Farmers and rural SMEs often find it difficult to appreciate how broadband can add value to their business and thus may feel that they will not benefit from its use (DEFRA, 2005; Warren, 2004). On the other hand, many householders will be employed by a few large employers such as local authorities and are therefore more likely to experience broadband in their employment and thus adopt.

A third feature of Figure 9 is that $100 \%$ adoption is not reached and, indeed, the rate of adoption slows down well before this level is reached. However, the rate of adoption does not completely stop during the 20 -year period. Although very gradual, there is continual evidence of adoption. The main reason for this outcome is due to the expected changing composition of the overall population in rural and remote Scotland. Although population forecasts do not anticipate the total number of population to dramatically change (Register General for Scotland, 2005), there is an expectation of in-migration from central Scotland resulting in a large percentage of the population having experience of broadband and thus wishing to adopt it in rural and remote Scotland (Hope et al., 2004).

Figure 9: Simulation model output assuming no future policies implemented to promote broadband adoption

ABOUT HERE 
It should be noted that the nature of some of the data used to populate the model meant that sensitivity analysis was required in order to explore the impact on model behaviour when model inputs were changed. Although the position of the two time series shown in figure 9 altered during sensitivity analysis, the three features described above were reasonably robust i.e. S-shaped growth, business adoption lagging behind household adoption and not reaching 100\% adoption. Figure 10 illustrates the impact on the simulation output when the weightings that should be applied to the key factors which were believed to influence the decision of a householder whether or not to adopt broadband (see figure 3 ) were altered. The five time series represent the use of different weightings including extremes such as having all the weighting put on just one criteria. The result is that the main conclusions of S-shaped growth and not reaching 100\% adoption still hold with only a small variation in the slope of the time series.

Figure 10: Sensitivity analysis for the weightings included in the householders decision criteria

ABOUT HERE

If the socio-economic benefits arising from the use of broadband are to be achieved in rural and remote Scotland, policies initiatives are required in order to speed up the diffusion process. With respect to Figure 9, this means implementing policies which either increase the slope of the curve or lift the point at which adoption slows down. Returning to the causal model, each of the inputs to this model were explored as potential areas for policies initiatives to focus upon.

Making changes to many of the inputs to the causal model was seen to have an impact on the slope of the graphs. For example, Figure 11 shows the impact of policies to encourage the appreciation of broadband attributes. This was implemented midway through 2007 in the model. Time series 1 and 2 are the original output from the simulation model. Time series 3 and 4 represent the diffusion curves after the policy has been implemented. There is minimal impact to the diffusion of broadband adoption amongst householders, however the slope of diffusion amongst businesses has increased.

Many of the inputs impacted the overall decision criteria for a business or a household and changing the factors contained in the decision criteria did not have a significant impact on the results as it was assumed that a number of factors contribute to a household or business' decision to adopt.

Figure 11: Implementing policies to encourage the appreciation of broadband attributes ABOUT HERE 
However, the most significant change in output was gained from the simulation when changes were made to those factors that impact the pool of potential adopters i.e. lifting the point at which adoption slows down. Exploration of the causal model indicated that the limited pool of potential adopters is restricting broadband adoption and the quantitative model has confirmed that this will remain a constraint in the long term. Therefore, policies that could potentially have the largest impact on adoption are those that could target and reduce the number of households and businesses that believe that they don't want the Internet, or in fact a PC, at all. It is appreciated that many of these people may never wish to experience the Internet or PC. However, an understanding of the needs of these people is required to explore whether or not there are particular services they could benefit from and thus enable them to experience the socio-economic benefits of broadband. If, for example, it was assumed that the number who believed they do not want the Internet or a PC halved, the resulting diffusion curve would be as shown in figure 12 .

Figure 12: Halving the number of people who not want the Internet, or PC, at all

\section{ABOUT HERE}

\section{Policy Discussion}

It has been highlighted that a key group of people to target is the number of households and businesses that believe that they don't want the Internet, or in fact a PC, at all. Policies that could be adopted to target this group include the following:

- Focused marketing campaigns. This is not a new policy but rather the restatement of an old policy that stopped once availability was achieved. These campaigns, in contrast to those in the past, will target key groups of businesses and households with low broadband adoption rates.

- Local Champions. Broadband could be brought closer to those who have not yet adopted through community based local champions.

- Incentives. For many it could be argued that broadband is increasingly affordable, but in rural and remote Scotland incomes are substantially less with the consequence that it is more of an issue. Although those people who are simply not interested in the Internet are unlikely to be swayed by a reduction in subscription cost, introducing incentives such as providing new computer equipment as well as demonstrating the benefits it could bring may trigger their interest.

- Online public services: The move of public services online could be used to force adoption but this would inevitably result in disenfranchisement of some parts of society. Online tax filing has proved to be more successful than anticipated, though whether it has the same sort of attractiveness in rural and remote areas is another matter.

- Understanding the needs of 'those not interested': By definition, those people who are not interested in the Internet at all, are not motivated by any particular service. Thus a 
study into the attractiveness of services to this particular group may allow for tailored campaigns to be developed that would encourage uptake by this group. In addition, there is a more general issue of identifying whether a 'killer application' for broadband actually exists.

\section{Conclusions and future research}

Although this paper focuses on broadband within rural and remote Scotland, particular attention has been spent on understanding the drivers of adoption. Through a series of policy initiatives, some of which were UK wide and some of which were Scotland specific, broadband is now available to almost all communities within rural and remote Scotland. Following this there was a reduction in advertising by the regional development agencies that coincided with the ending of BT's trigger lists and the availability of broadband in most Scottish telephone exchanges. However, this does not mean that everyone actually has adopted broadband. Broadband has been adopted more in urban areas than rural and remote areas, with the consequence that the undoubted benefits of adoption are not being enjoyed in these areas. Thus, the first conclusion that we can make is that policy initiatives need to be developed that focus on adoption even when broadband is available.

Understanding the drivers of broadband adoption and their interaction was believed to be key to the development of appropriate policy initiatives. Therefore, a causal model was developed using various data sources. From this model it was concluded that past policies have had the greatest impact on the rate at which potential adopters have adopted broadband, however, they have not directly impacted on the pool of potential adopters thus restricting the uptake of broadband.

This conclusion was reinforced with investigation through a quantitative simulation model. In particular, it has been suggested that future policies that could potentially have the largest impact on adoption are those that target and reduce the number of households and businesses that believe they do not want the Internet, or in fact a PC, at all.

The above conclusions highlight the need for policymakers to address broadband adoption. It is hoped that through the dissemination of the results to all parties involved in the data collection process that key policymakers within Scotland will use the results to support future efforts to develop appropriate policies.

Although this paper has focused on rural and remote Scotland, it has implications for other rural and remote areas around the world. In localities as diverse as Alaska (Hudson, 2006), Scandinavia (Lindmark and Björstedt, 2006) and Germany (Lattemann, 2006) there is a desire to ensure that broadband is available and then adopted by all those who live in rural and remote areas as well as urban areas. Through identifying the drivers of adoption as well as appropriate policy initiatives, the models suggested here could be mapped onto other geographies. Although the model developed in this paper focuses on rural and remote Scotland, much of its structure would apply to many urban areas. Urban areas are not homogeneous, differing in terms of population densities, income and communication use. Integral to the models articulated in this paper is the notion that adoption is driven by a series of uses that differ depending on the circumstances of the 
business or household. The models have identified in which general areas future policy initiatives should be developed. By understanding the impact of the different services on adoption, future research will result in more tailored policy initiatives. Future research can also be undertaken that targets those who express no interest in adopting broadband. The understanding of how services impact on this group is unclear, and thus crucial to increasing broadband adoption.

\section{References}

Andersen D and Richardson G (1997). Scripts for group model building, System Dynamics Review 13(2) pp107-129.

Bauer JM, Kim JH and SS Wildman (2005). Effects of national policy on the diffusion of broadband in OECD countries, paper presented at the UFL-LBS Workshop The future of broadband: wired and wireless, February 2005.

Bass FM (1969). A new product Growth Model for Consumer Durables. Management Science 15 (5): pp 215-227.

Biggs P and Kelly T (2006). Broadband pricing strategies, Info 8 (6): 3-14.

Brignall S (2006). Broadband and phone services going down the tube, say customers, 14 November. The Guardian, available at technology.guardian.co.uk

Cava-Ferreruela I and Alabau-Munoz A (2006). Broadband policy assessment: a crossnational empirical analysis. Telecommunications Policy 30 (8/9): 445-463.

DEFRA (2005). ICT in England's rural economies: A final report to DEFRA, available online at www.defra.gov.uk

Fildes R and V Kumar (2002). Telecommunications demand forecasting - a review. International Journal of Forecasting 18: 489-522.

Forrester JW (1961). Industrial Dynamics. Productivity Press: Portland, Oregon.

Forrester JW and PM Senge (1980). Tests for building confidence in system dynamics models, in, Legasto AA Jr., Forrester, JW and JM Lyneis, Editors, TIMS Studies in the Management Sciences 14.

Fransman M (2006). Global broadband battle - why the US and Europe lag while Asia leads. Stanford Business Books: Stanford, California.

Galloway L and Mochie R (2005). The use of IT in rural firms: a policy-orientated literature review. Info 7 (3): 33-46.

General Register Office for Scotland (2004). Household projections for Scotland: 2002based, available online at www.gro-scotland.gov.uk

Geroski PA (2000). Models of technology diffusion. Research Policy 29(4/5): 603-625.

Hollifield CA and Donnermeyer JF (2003). Creating demand: influencing technology diffusion in rural communities. Government Information Quarterly 20(2): 135-150. 
Hope S, Murray L and Martin C (2004). In-migration to the Highlands \& Islands, NFO Social Research, Edinburgh

Hudson HE (2006). From rural village to global village. LEA: Mahwah, New Jersey

ITU (2003). Birth of broadband - ITU Internet reports, ITU: Geneva

ITU (2006). Trends in telecommunication reform 2006 - Regulating in the broadband world, ITU: Geneva

Kim M and Kim H (2004). Innovation diffusion of telecommunications: general patterns, diffusion clusters and differences by technological attribute. International Journal of Innovation Management 8(2): 223-241.

Lattemann C (2006) Public Private Partnerships im Brietbandsektor - Fallbeispiele aus den Ländern Schweden, Großbritannien, Frankreich und Deutschland. MMC Multimedia Campus Kiel: Germany

Lindmark S and Björstedt P (2006). The Swedish broadband market, in, Fransman, M Editor, Global broadband battle - why the US and Europe lag while Asia leads. Stanford Business Books: Stanford, California

Lyons MH, Adjali I, Collings D and Jensen KO (2003) Complex systems models for strategic decision making. BT Technology Journal 21(2): 11-27.

Madden G and Simpson M (1997). Residential Broadband Subscription Demand: an Economic Analysis of Australian Choice Experimental Data. Applied Economics. 29 (8): 1073-1078.

Mahajan V, Muller E and Wind J (1990). New product Diffusion Models in Marketing: A Review and Directions for Research. Journal of Marketing 54 (1): 1-26.

Mahajan V, Muller E and Wind J (2000). New-Product Diffusion Models. Dordrecht, Netherlands: Kluwer Academic Publishers.

Maier FH (1998). New Product Diffusion Models in Innovation Management - a System Dynamics Perspective. System Dynamics Review 14(4):285-308

Milling PM (1996). Modeling Innovation Processes for Decision Support and Management Simulation. System Dynamics Review 12(3): 211-234.

National Statistics (2003). Yearbook 2003 - The Official Yearbook of the United Kingdom of Great Britain and Northern Ireland. Office of National Statistics: London

Ofcom (2004). The Ofcom Internet and broadband update, April. Ofcom: London

Ofcom (2006a). The Communications Market: Nations and Regions, April. Ofcom: London

Ofcom (2006b). The Communications Market: Nations and Regions - Scotland, April. Ofcom: London

Ofcom (2006c). Media literacy audit: report on media literacy amongst people in the nations and regions, April. Ofcom: London

Ofcom (2006d). The Communications market 2006, 10 August. Ofcom: London. 
Ofcom (2006e). Policy implications arising from the Communications Market: Nations and Regions research, 12 October. Ofcom: London.

Oh S, Ahn J and Kim B (2003). Adoption of Broadband Internet in Korea: The Role of Experience in Building Attitudes. Journal of Information Technology 18 (4): 267280.

Osborne J (1999). Dynamic Modelling to Assist in the Understanding of Consumer Takeup and the Diffusion of New Telecommunications Services, paper presented at the 17th International Conference of the System Dynamics Society and 5th Australian \& New Zealand Systems Conference, 20-23 July, Wellington, New Zealand

Ovum (2006). UK broadband status summary March 2006 - covering the period October 2005 to end December 2005. A report for the Department of Trade and Industry, Ovum: London

Parker PM (1994). Aggregate diffusion forecasting models in marketing: a critical review. International Journal of Forecasting 10: 353-380.

Registrar General for Scotland (2005). Projected population of Scotland (2004-based), HMSO: Edinburgh.

Roberts JH and Lattin JM (2000). Disaggregate-Level Diffusion Model in V Mahajan, E Muller and Y Wind, Editors, New-Product Diffusion Models. Springer: New York.

Robertson A, Soopramanien D and Fildes R (2004). Understanding residential Internet service adoption patterns in the UK, Teletronikk issue 4: 84-94.

Rogers EM (2003). Diffusion of Innovations, $5^{\text {th }}$ Edition. Free Press: New York

Saeed K (1998). Constructing reference mode. Paper presented at the $16^{\text {th }}$ International Conference of the System Dynamics Society, Quebec City.

Savage SJ and Waldman D(2005). Broadband Internet Access, Awareness and Use: Analysis of United States Household Data. Telecommunications Policy 29: 615-633.

Scottish Enterprise (2004). Still time to plug into broadband payment, 26 January, available at www.scottish-enterprise.com

Scottish Executive (2001a). Connecting Scotland, Scottish Executive: Edinburgh.

Scottish Executive (2001b). Digital Inclusion, Scottish Executive: Edinburgh.

Scottish Executive (2002). Making it happen, Scottish Executive: Edinburgh.

Scottish Executive (2005). Scotland's people: annual report: results from the 2003/2004 Scottish household survey, Scottish Executive: Edinburgh.

Sterman JD (2000). Business Dynamics: Systems Thinking and Modeling for a Complex World. Irwin/McGraw-Hill: Chicago.

Strover S (2001). Rural Internet Connectivity. Telecommunications Policy 25(5): 331347.

Teng JTC, Grover V and Guttler W (2002). Information technology innovation: general diffusion patterns and its relationships to innovation characteristics. IEEE Transactions on Engineering Management 49: 13-27. 
Tookey A, Whalley J and Howick S (2006). Broadband diffusion in remote and rural Scotland. Telecommunications Policy 30 (8/9): 481-495.

Varian H, Litan RE, Elder A and Shutter J (2002). The Net Impact Study: The Projected Economic Benefits of the Internet in the United States, United Kingdom, France and Germany, available online at http://www.netimpactstudy.com

Vicente MR and Lopez AJ (2006). Patterns of diffusion across the European Union. Economics Letters 93: 45-51.

Vigden R, Francis D, Powell P and Woerndl W (2004). Web Service Business Transformation: Collaborative Commerce Opportunities in SMEs. Journal of Enterprise Information Management 17 (5): 372-381.

Warren M (2004). Farmers online: drivers and impediments in the adoption of Internet in UK agricultural Businesses. Journal of Small Businesses and Environment Development 11(3): 371-381.

Whalley JL (2005). Local loop unbundling in the United Kingdom: strategic reviews, institutional responses and equivalence, paper presented at International Telecommunications Society European Regional Conference, Porto, Portugal, September. 
Figure 1: Scotland

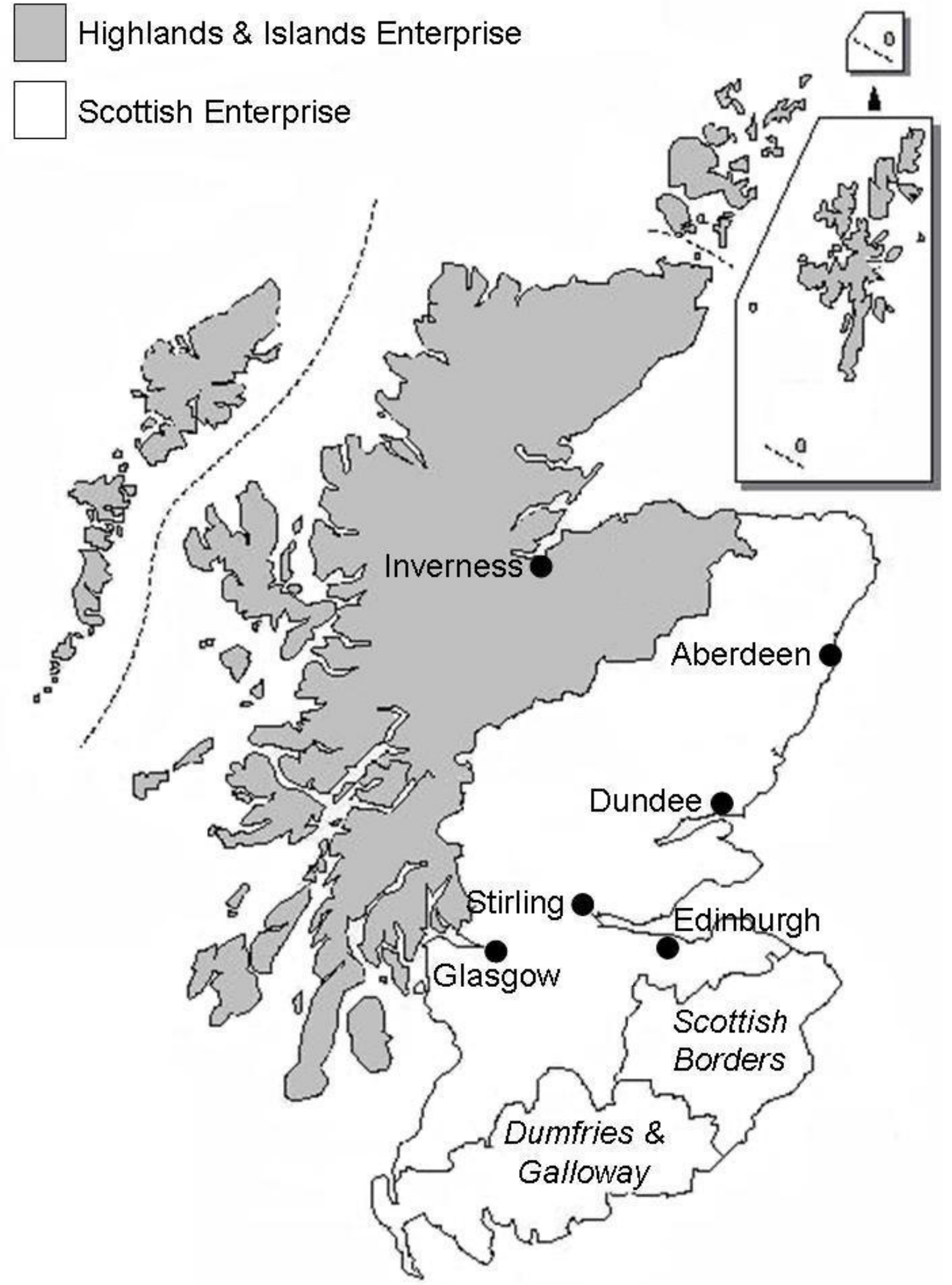


Figure 2: Causal Diagram representing the Bass Diffusion Model

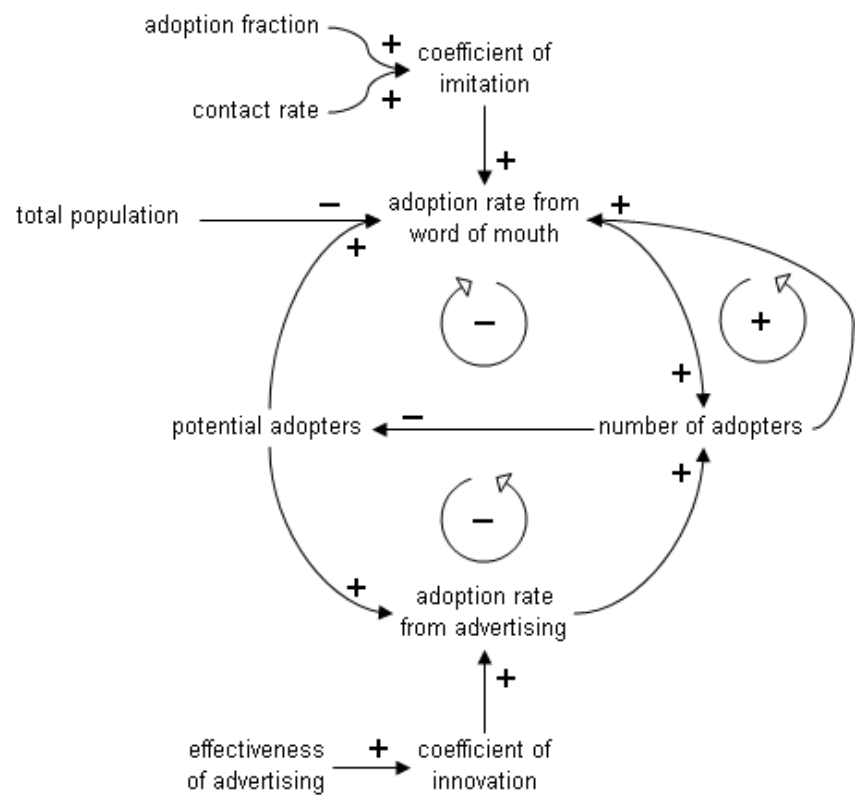


Figure 3: Key factors affecting decision criteria for households with dial-up

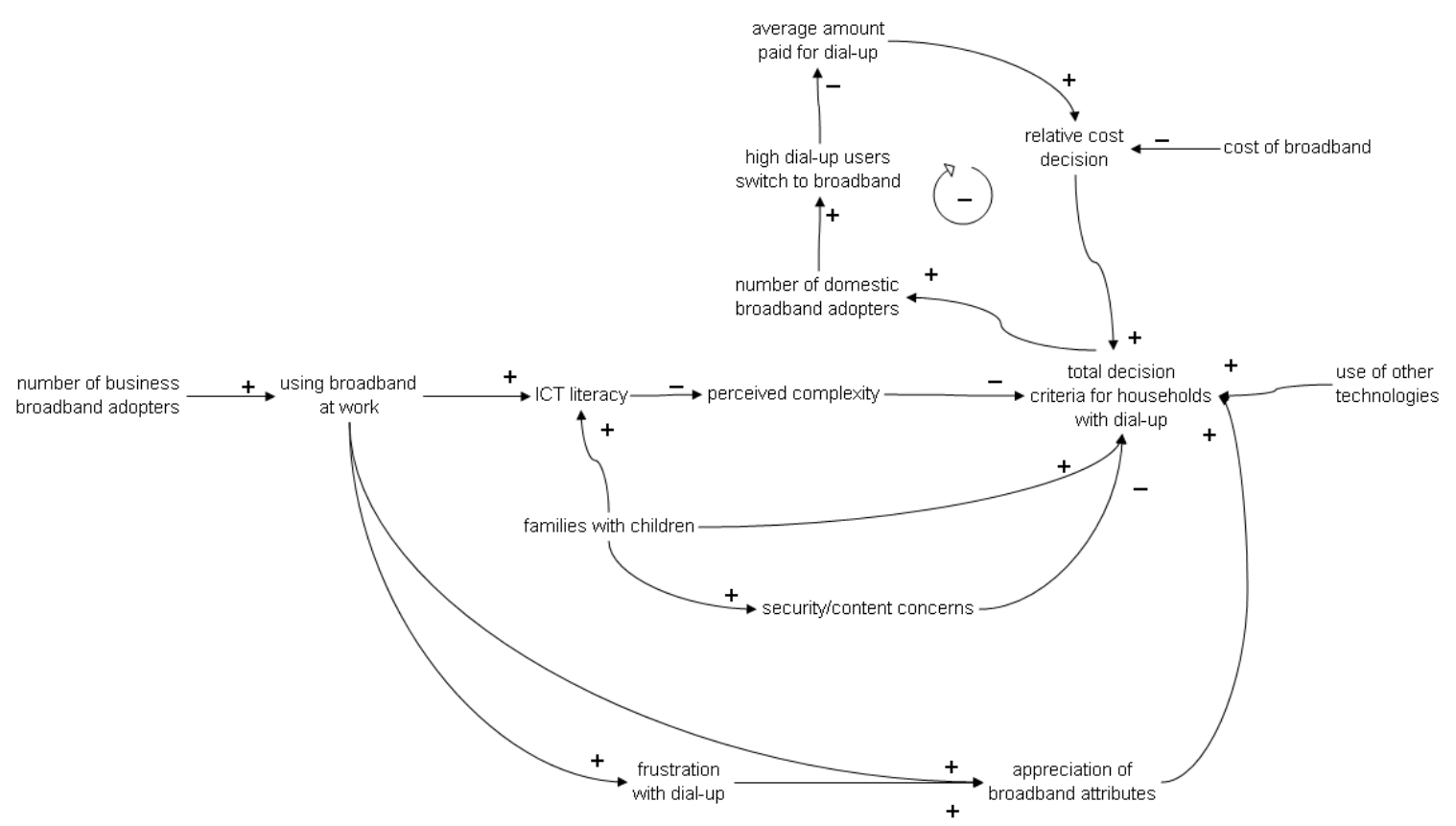


Figure 4: Key factors affecting decision criteria for businesses with dial-up

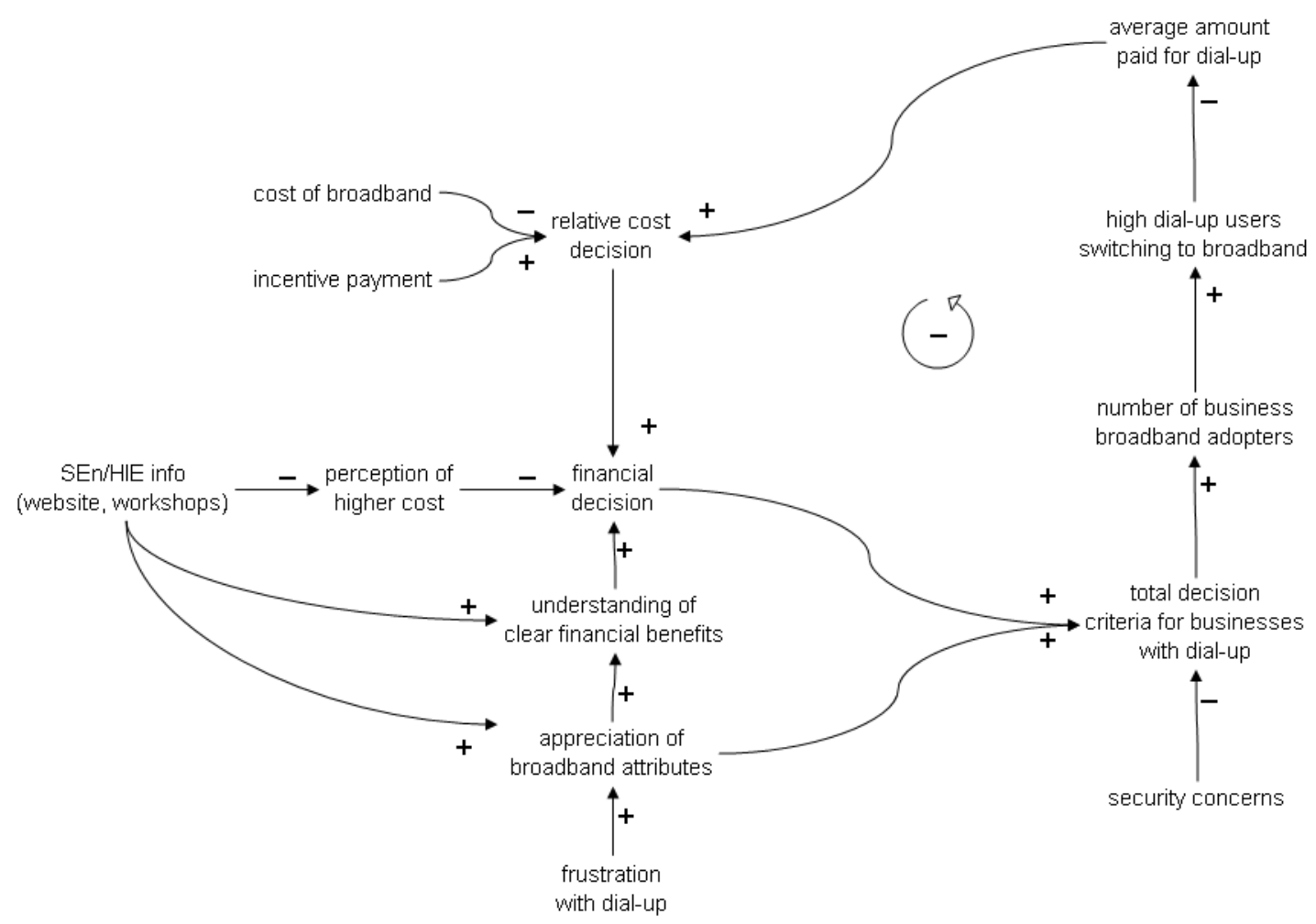

Figure 5: Key factors that influence the pool of households without dial-up that are potential broadband adopters

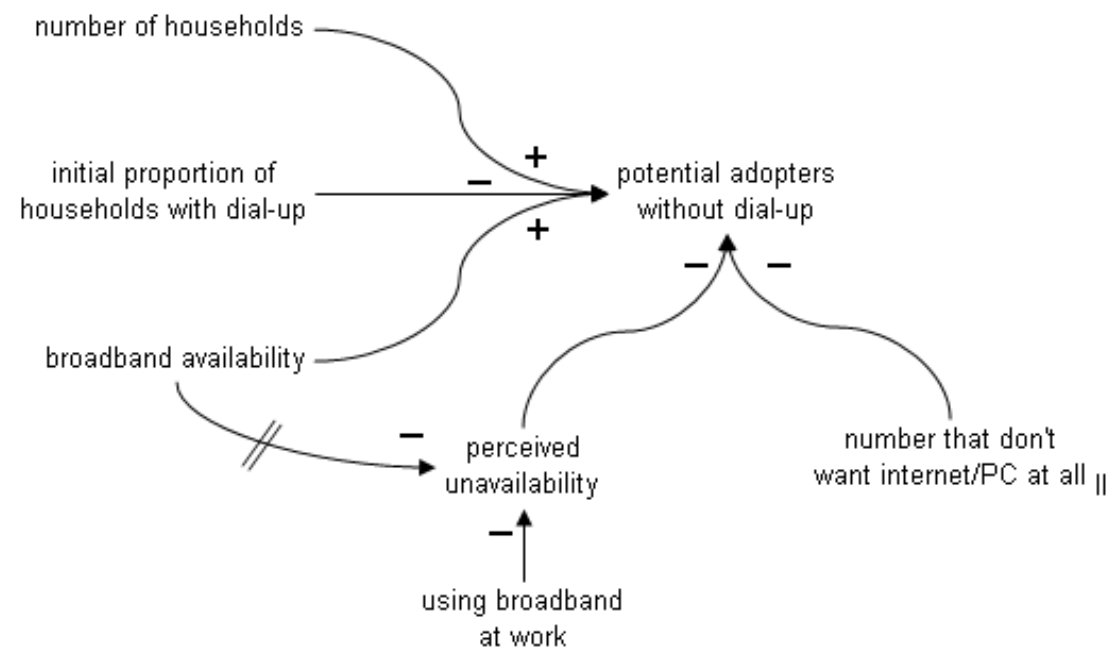


Figure 6: Key factors that influence the pool of businesses without dial-up that are potential broadband adopters

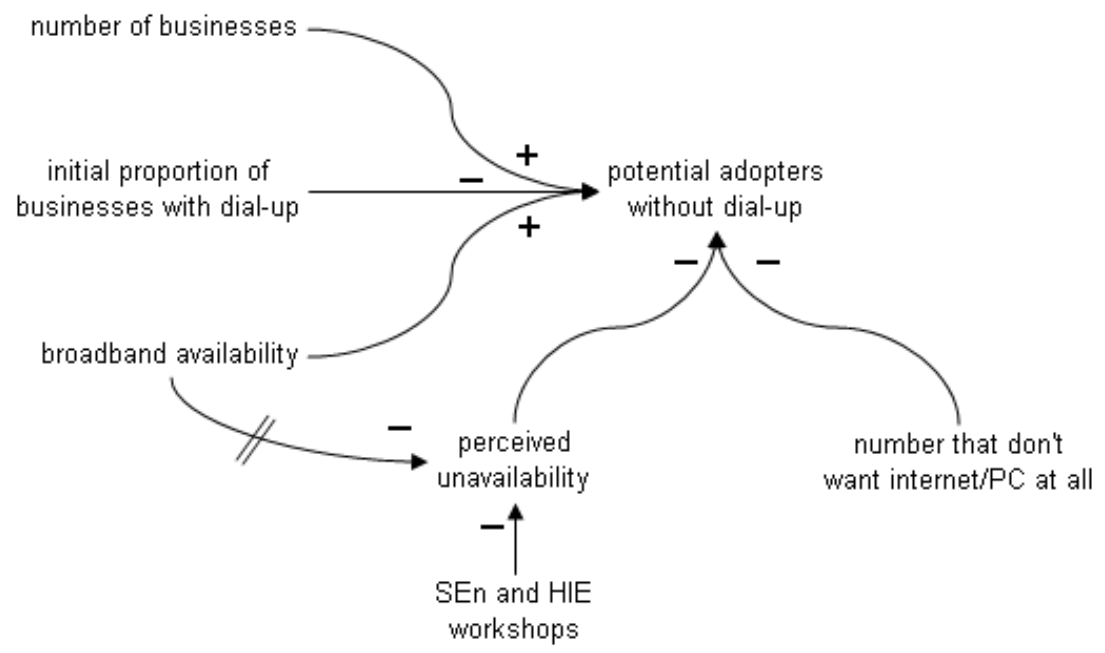

Figure 7: Key factors that influence advertising

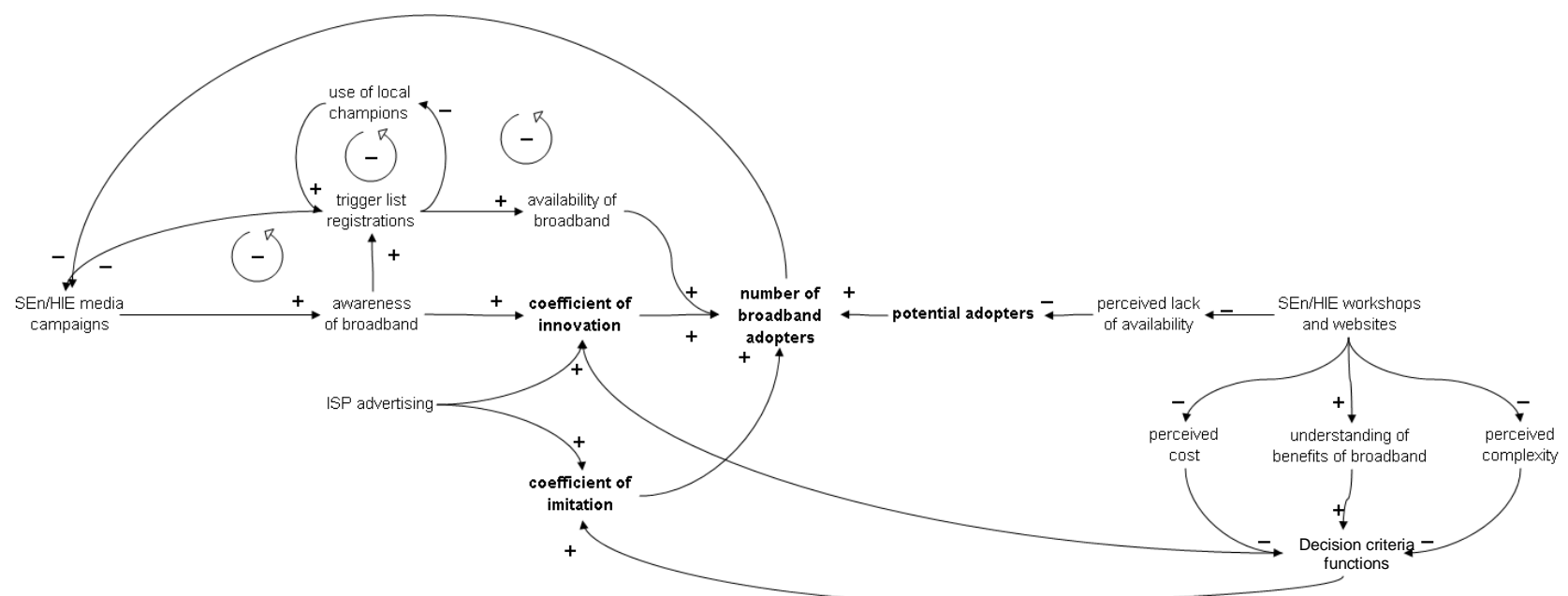


Figure 8: Portion of System Dynamics model capturing factors that influence broadband adoption for businesses without dial-up

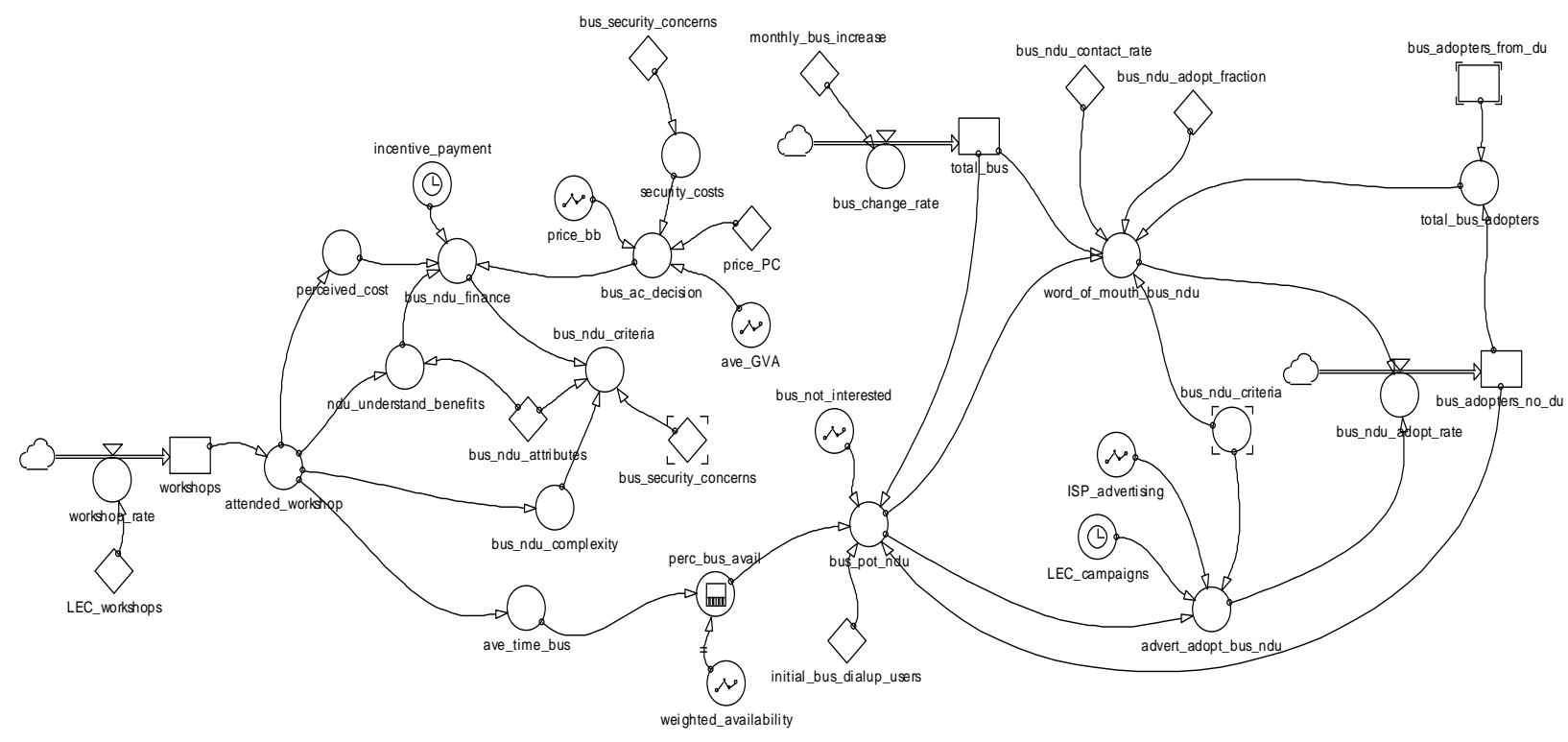

Figure 9: Simulation model output assuming no future policies implemented to promote broadband adoption

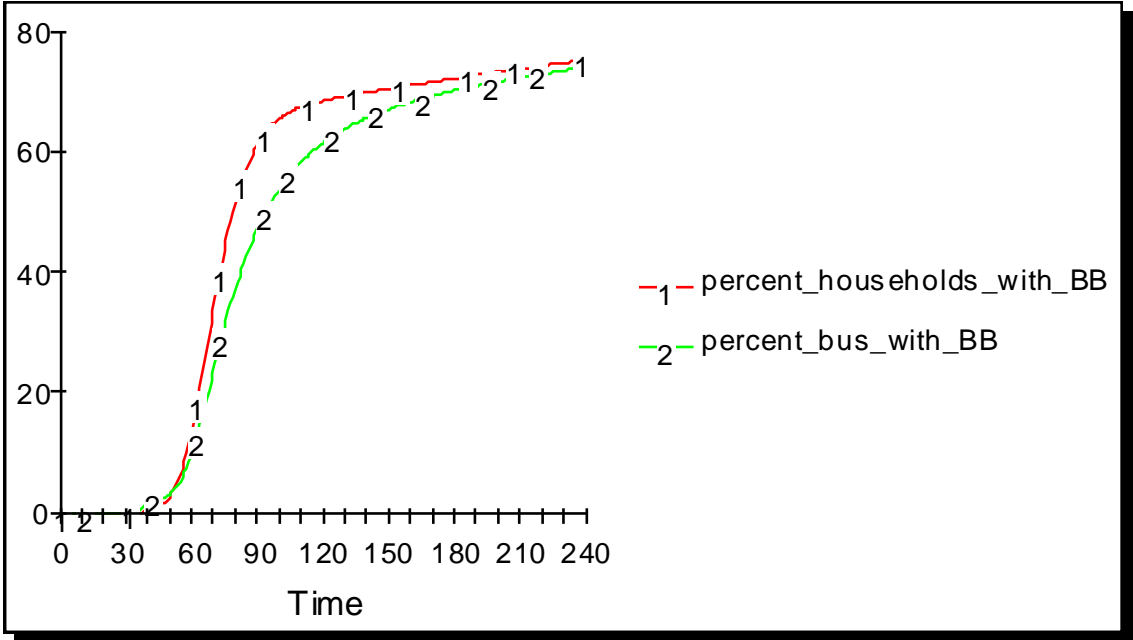


Figure 10: Sensitivity analysis for the weightings included in the householders decision criteria

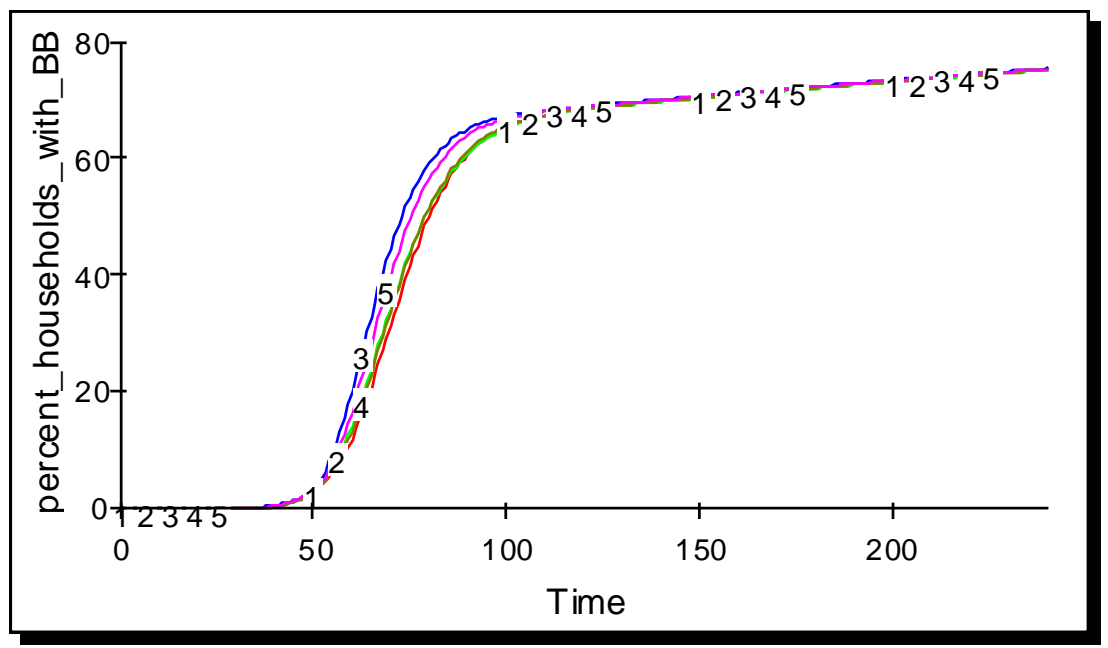

Figure 11: Implementing policies to encourage the appreciation of broadband attributes

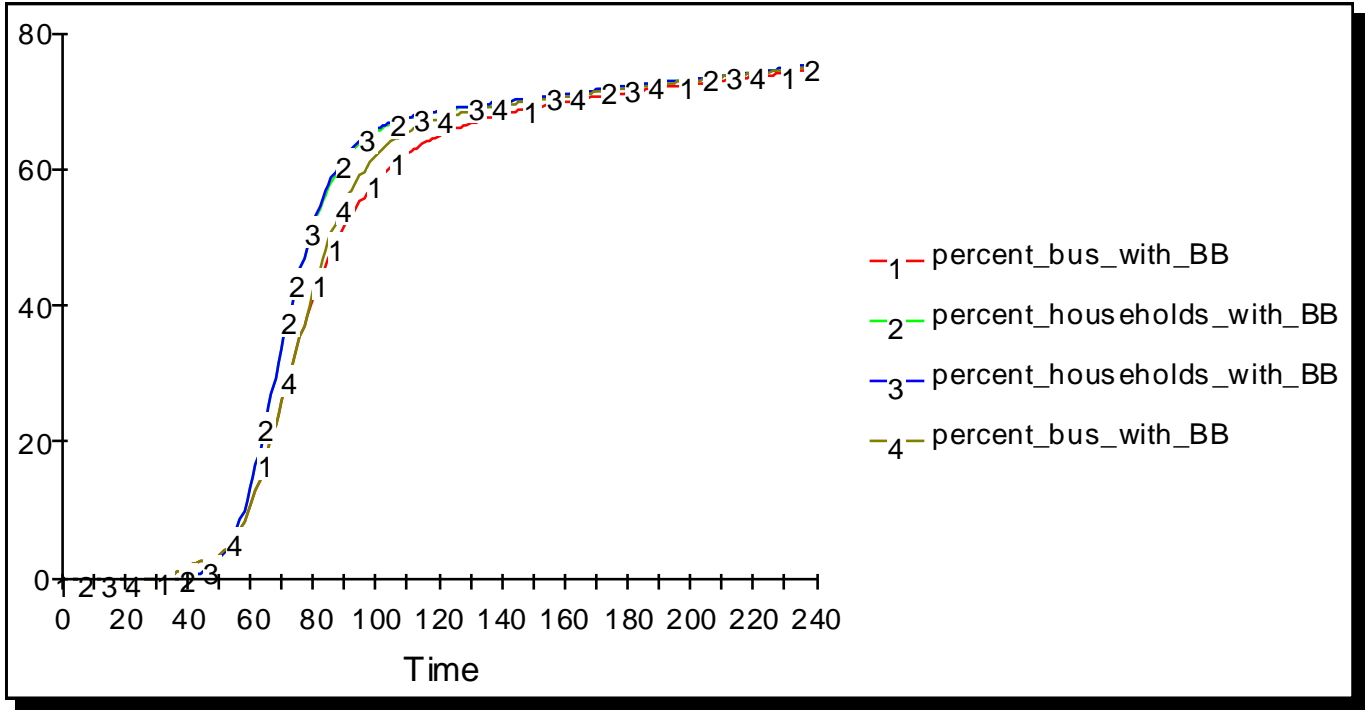

Figure 12: Halving the number of people who not want the Internet, or PC, at all 


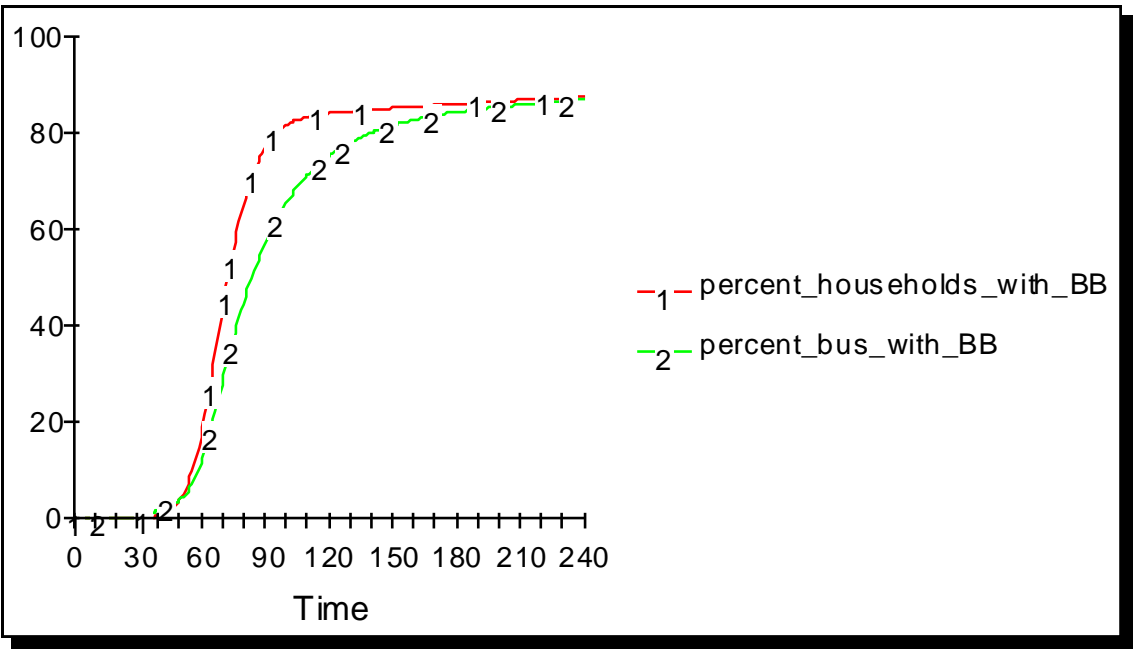

